\title{
Visualising and regenerating brownfields in the Czech Republic
}

\author{
J. Bergatt Jackson \\ IURS-Institut pro udržitelný rozvoj sídel o.s., Czech Republic
}

\begin{abstract}
This paper critically addresses the legal identification of brownfields in the Czech Republic, which the new Planning and Construction law enabled. It lists the advantages and the disadvantages of the Czech approach towards the visualising of brownfields and gives examples, where and why the law is not effective and suggests how it can be adjusted or the situation improved. The paper develops an argument that, in spite of various sources of publically accessible brownfield databases, Czech brownfield identification is still not consistent or effective, and supports this by examples. A description of the "Community inventorying approach" is included, which is exploiting the possibilities offered by the recent legal changes. This new approach was developed with the aim to improve and regularly update the existing regional data sets and to give the communities easy tools to understand their brownfields. Also demonstrated is the need for analytical output from brownfields databases, which would help the regions and the communities to understand their regional and local trends. The paper also explains the effect of previous data insufficiency onto EU Structural Funds funding priorities for brownfields' regeneration.
\end{abstract}

Keywords: brownfields regeneration, brownfields inventorying tool, community orientated information, brownfields databases.

\section{Introduction}

Urban regeneration and brownfields reuse improve local land economies and aid sustainable land use. Related development activities then help to convert local plans into reality. They also reflect onto local ability to manage and steer local development processes, attract and coordinate private and public investments and provide quality public domain and ample public benefits. The success of 
urban regeneration however depends on many factors. Strong local leadership and sophisticated governance are, in most instances, one of the main deciding forces, especially in the non-prime areas. Local development decisions therefore need to be well informed based on knowhow and on solid data analyses. But the actual individual urban investments are carried out by various private or public bodies; the financing is controlled by private institutions or public grant programs, the technical and legal implementation is governed by the national/regional sets of rules and regulations. Hence on any successful local urban regeneration usually cooperates a broad spectrum of stakeholders. The national level stakeholders need to set up number of pre-conditions, which would enable to address successful local brownfield regeneration. These especially are:

- clear labelling and identifying brownfields as an "issue" to be addressed,

- including brownfield issue in the national policy priorities,

- differentiating regionally the varied size and type of brownfields issue,

- providing initial funding for research and expertise development through pilot project, programs and inventories,

- improving development knowhow for all stakeholders and on all levels (projects LEPOB, BRIBAST, COBRAMAN, CIRCUSE est.),

- amending legal framework, so that brownfields are "seen" by spatial planning and are integrated into a wider framework of urban development,

- enabling the Technical Assistance in the most effected regions and cities.

\section{Brownfields visualization}

\subsection{Past inventorying efforts}

Sizing and analysing the brownfield issue is important for building up an understanding of the nature and seriousness or the problem. Past inventorying of brownfields in the Czech Republic, brought about a set of challenges revolving around brownfields input into spatial and strategic planning. The initial survey in 2004 estimated existence of about 10,000 (+, - 2,500) sites nationally and the consultants stressed out the urban context of the issue. Subsequent surveys by the CzechInvest in 13 Czech regions focused only on larger sites suitable for the industrial reuse (above 2 hectares or including a building over 500 square metres). This has yield data on just over 2000 sites. In addition, after 2006 some regions and larger cities began to compile their own, more detailed inventories. These lacked national coordination and a common methodology, making the data incompatible. Also, when the initial inventories began to emerge, so did new sets of problems surrounding the release and use of this data. In particular, as listing in such an inventory might have stigmatised the property development potential. Thus questions were raising, who might be authorised to undertake such listings, and on what basis and to whom the data should be accessible. For example: initially, the owners of only 130 properties agreed to publish details regarding their sites in the large and costly CzechInvest survey (it was only the "vision" of SF finance that had improved owners" publicity "willingness"). 


\subsection{The new law and its effects on visualising brownfields}

The Czech New Planning and Construction law was passed in 2006 and become valid a year later. The law beside other things sorted out the issues related to brownfields on several points:

a) it visualised brownfields for planning (previously brownfields was not know category in planning), b) it has given qualified planners the right to stigmatised properties as brownfields, c) it has cleared out the brownfield data publicity issue, d) it has provided bases for a regular brownfield inventorying and data update in administrative units called ORP.

The new law related degree required the identification of brownfields as one item (Item 4) of the 120 other land use data items compiling the GIS layers of the new nationwide planning support system (UAP). The law had placed duty on all the Czech local authorities (6250 in numbers) to provide surveys of their brownfields and update such data in intervals of 2 years. Nominated local authorities ORPs (205 in numbers) are required to collect all GIS data and publish on the Internet their main findings. By 2008-9, when the new legal requirements were performed for the first time, the shortcomings in brownfield inventorying efforts appeared and it became apparent that improvements were needed (to coordinate the 205 different approaches to brownfields inventorying). There were several mayor areas of problems:

1. terminology mixing, which can be solved by subdividing the "Jev4" into several layers, thus helping to keep brownfields separate from other land types determined for redevelopment,

2. data structure, its "communication" to lay persons and its suitability to share such data between planning and strategic departments - this can be solved by qualitative information added to the listing in the GIS attributes and polygons (photo, an assessment of the owner's ability to improve the property, rough evaluation of the likelihood for market uptake of the property est.),

3. lack in compatibility and consistency of data - this can be solved by adopting a common methodology and by providing training (focussed especially on collection of qualitative criteria and additional attributes in order to avoid subjectivity and inconsistency in classification),

4. 2 year frequency of survey for brownfields is proving to be too expensive and consideration should be given to 4 year bases - law would need amending on this.

5. legal duty to coordinate and handle brownfield data from ORPs was not given to regional level - this can be easily changed by nationally based "motivating" program (aimed on improving the regional interest to coordinate) or possibly by amendment of the law.

By 2008 most of the Czech regions had some brownfields inventories either managed by their departments of the Industrial, or the Strategic development. These databases are usually approached from the point of brownfields marketing and promotion and offer only very limited analytical outputs. Also, these departments were initially totally unaware of any inventorying compiled under the auspices of the new planning law and carried out in the ORPs planning 
departments. Horizontal/vertical communication between individual departments is not very good hence the potential for having on regional level publishable and updatable brownfield data was being lost. Further barrier laid in the prescribed GIS format of data, which have suited the spatial planners but not the strategic planners.

\subsection{Advantages and barriers to brownfields data use}

Regions and the local communities, which have large amount of brownfield land, need to understand the nature, the size and the seriousness of their problem. But gathering of brownfields data alone does nothing to promote local brownfields reuse and it cost money. To justify any inventorying, data need to be worked with, analysed and incorporated into plans, strategies and policies. Analytical findings arising from the gathered data can be useful for both brownfields redevelopment support and also for spatial planning. Data analyses point out the nature of the issue and indicate the key points, which need to be addressed. This is why regions and communities need brownfield data. But they need data outputs in easily accessible IT technology formats. Firstly to lower the technology cost, and secondly to cope with the level of IT skills barriers. The other thing regions and communities need are formats of data, which offer easily procurable and "communicative" outputs. (It is not very easy to communicate to anyone a line of GIS polygon attributes...). What are needed are easily produced graphical outputs, giving information about single brownfield and also analytical outputs about groups of brownfields.

\section{Search for improvements -"communicative" and "local" brownfield inventories}

In 2009 a methodology approach to community inventorying in the Czech Republic was developed and financed from the Central Europe project COBRAMAN, through a commission of the project partner, city Ústí nad Labem. Methodology was prepared by IURS, a non-profit Civic Association aiming to support sustainable urban development. An experience of practical participation on several of brownfields surveying pilot projects and research and an evaluation of various databases compiled by previously created surveys set the bases for IURS particular approach. IURS also reacted on the experience and the needs of relevant departments and stakeholders. The main aims were:

- provide outputs of data required by the new law and suitable for purposes of spatial planning,

- provide an effective comparable data surveys with minimal costs,

- provide data in a form supporting analysis, benchmarking and other community development use,

- provide accessible outputs to enable the local departments to advocate the brownfields issue: indicators, printed brownfield cards with photos and locations, graphs and simple maps. 


\subsection{The survey}

An effort for effectiveness and cost reduction led into splitting of the survey into several stages: a) start up training, b) fieldwork stage, c) expert stage, d) GIS stage, e) analytical stage. The survey supervision and a help line for the staff is offered and recommended, in order to improve data quality and comparability. Surveys in such a shape and quality can be also used for other purposes such as sustainability assessment, EIA, SEA est. Analysing brownfields data and GIS layers enable number of sustainability and brownfields indicators and market information.

\subsubsection{Start up training}

Start up training is offered to all survey staff. The technical staff and the experts are trained indoors how to use the simple .xls format inventorying tool, where to find required information and how their work relates to each other. The outdoor training concentrates on their ability to recognise various types of brownfields and to unify their perception of brownfields in order that they are able to fill in correctly the qualitative sections of the inventorying tool. IURS offers to Czech regions such survey training for their ORPs, with an aim of unifying procedure and data characteristics across the region. It is in everybody interest to have a comparable data in various administrative areas.

\subsubsection{The fieldwork stage}

The fieldwork stage takes place mainly outdoors and it is carried out by the technical staff. The survey staffs begins with studying existing brownfields surveys; checks the actual status of already identified brownfields; and records new and "presumed" brownfields. The cost of the fieldwork is minimalized by focusing on qualitative data. Quantitative data can be added in the office from GIS and other IT sources.

\subsubsection{The expert stage}

The expert stage takes place mostly indoors. It is carried out by an expert planner, as required by the new planning law. Expert checks and reviews the data for correctness and completeness and enters in the individual brownfields use classification.

\subsubsection{The GIS stage}

The GIS stage of the survey consists of updating the GIS layer and polygons attributes from the inventorying tool .xls database. This is followed by drawing up the newly identified brownfields polygons and if need be, by amending the existing ones. The survey uses GIS for several reasons. The law prescribes the use of digital technology in order to "facilitate data exchange for use of the region". At the same time, there are many other data already created in GIS (e.g. floodplain, preserved areas, technical infrastructure and so on). GIS data can be easily exported into different format, e.g. xls; and the proposed inventorying tool can therefore work with the GIS attributes data; and enable analysis of various 
data in hand. Last but not least, the .xls format does not represent such skill and cost barrier as does the GIS.

\subsubsection{The analytical stage}

The analytical stage has two forms of outputs. The first output consists of compiling analyses from numberless graphs (see Figure 2 for an example), which are automatically generated by the inventorying tool (see Figure 1). The inventorying tool also generates a set of indicators, either for the whole ORP or for a selected community (see Table 1). For example, such analyses have shown that the present level of brownfield remediation in the city of Ústí nad Labem is absolutely insufficient. At that level it would take cc. 375 years, before the city could sort out their brownfields (assuming that no new brownfields occur). The indicators help to compare brownfields threat in different ORPs and different communities. The second output is graphical analyses. They are prepared by the GIS technical staff and consist of several simple communicative maps (A4/5 format) identifying spatially min 3 different classifications, selected from the data inventory. For an example of communicative power of this output see maps pictured in Figure 1. The other graphical outputs, as required by the new law, are based on the GIS brownfields polygons.

\subsection{The Inventorying tool - Brownfield Card}

The card was conceived as a tool, which would assist ORP surveying staff, unify the data and help to fill and update the regional databases from the bottom up approach, with all the publicity and update advantages offered by the new law. The collected data and information is specifically tailored for the community's or the ORP use. Present Czech regional databases as illustrated in the section "References" are set up on different principles and communities cannot easily access and use their own data for their own analytical purposes. A simple .xls format database with individual Brownfield cards was devised. Card has a number of pre-selected menus to fill in with the individual brownfield information. Card also includes photos, a location map and an ortophoto, with a rufly marked up brownfield polygon. This and the GPS identifies the brownfield to the GIS technician, who draws the GIS polygons, based on the presented information and fitted onto cadastral map boundaries. The surveying tool automatically generates graphs for cc 30 different categories included on the Brownfield card. The tool can do graphs for the whole ORP or for a selected community only. It also automatically compares existing and new surveys on min 6 points and it analyse on min 4 points brownfields, which were already regenerated. It also automatically manages the size of the photographs. The main card text and the selection menus can be easily amended to any language, or to particular local needs (for example local plan land use categories varies from region to region). It can actually be used for any other item inventory (for example listed buildings). The strength of this approach, when comparing it to other much more sophisticated solutions, lies in its cheapness, ease of use in the terrain, simplicity and its ability to produce automatic analytical outputs. The inventorying tool also automatically generates and renews a set of brownfields' 
indicators. The legal requirement for regular inventorying updates enables following up of trends of what would actually be happening with local brownfields. The indicators also help objectively to compare the state and the trends of brownfields in different ORPs and different communities.

\section{Can brownfield data and analysis help brownfield re-use?}

None of Czech regional and national brownfields databases (see the included web literature) addresses a wider regional, community or urban context. All the databases concentrate on promoting a single site remediation. These promoted sites, providing they are in commercial locations and there is a market need for them, may get regenerated. Sites, which are not well located, and for which there is no market need, do not get regenerated. But the issue is not as black and white as that. It takes more to promote brownfield reuse then to visualise or aid individual sites. Local conditions need to be considered and understood and wider opportunities exploited. Even in the non prime locations, certain shifts and improved competitiveness can be achieved, if the local regeneration issue is well handled and understood. To achieve such shifts improved skills, suitable partnerships and quality understanding what is the nature of the problem are needed.

When addressing brownfield regeneration, solid and comparable data can be of a substantial help. Trends, changes and performance can be easily monitored. Analyses allow for formulation of informed strategies and actions. Analysing brownfields data and GIS layers gives number of sustainability and brownfields indicators and provides useful market information. This can prepare arguments for initiatives, programmes, marketing support and mitigating measures.

But any data gathering and analysis is meaningful only when their findings are being acted up on. That is: strategies are actually formed, they get real political support, stakeholders become "truly" involved, projects and funding are in place, actions are implemented and their outcomes are monitored! The data collection and also data analyses are only one of the "soft" measures needed to drive on the brownfields reuse support. The other soft measures are for example: improved knowhow, technical assistance to the local authorities and brownfields owners, promoting project preparation, suitable local planning est.

For the last 7 years most of the Czech Republic public support for brownfields concentrated therefore mainly onto "hard" measures and only a very little was channelled into the "soft" measures, which are usually much more cost effective. For example, measures helping to develop bankable brownfields projects are only very recently "budding" up. And when "soft" funding was considered, it was placed in a wrong institution, with an outcome of single brownfields sites remediation, lack of brownfields and urban regeneration skills amides local authorities, absence of literature and education material and minimal know-how transfer to any educational institutions. Even today the urban and the community context of brownfields is insufficiently addressed even thou, the possibility of an Integrated Urban Programs exist within all the Czech ROPs. It exists, but is seldom used. Cities and stakeholders lack brownfield 
regeneration skills, therefore, they usually take the easy way out (this apply for example to the IPRMs of Kladno, Zlín or Ústí nad Labem). Despite what is here stated, one must admit, that "the brownfield knowhow" in the Czech Republic is probably the highest amides the EU new member states and in the pier states even more profound problems exist.

\section{Aiding brownfields development - do inventories help?}

\subsection{SF "hard" measures drive}

In the Czech Republic, the "hard" funding measures have somewhat preceded the detailed analyses, strategies and urban project preparation. The SF programs had opened a window of opportunity for a single site brownfield refurbishment, which was based on limited and flimsy data. Some of these funds were spent on projects, which really did not need any funding (A types), or on projects with a very questionable sustainability ( $\mathrm{C}$ types).

In the Czech Republic brownfields were supported by public intervention since 2003. Public funds were available as gap finance for selected projects. As from 2004 it is mainly the Structural funds, which are used as a support for redevelopment of public and private brownfields projects. In the programming period 2007-13 there are two main sectoral programs orientated on environment and industry, which have useful brownfields priorities and there are the already mentioned Regional Operational programs (ROP) at the level of NUST 2. Yet again with mostly "hard" measures only! All the ROPs have experienced difficulties with brownfields data. Most of the databases have concentrated on larger brownfields and there was an absence of smaller urban properties, which were stigmatised as brownfields. ROPs brownfields priorities vary, as varies the regional perception of brownfields regeneration needs and so the smaller brownfields recognition absence was dealt on "regionally". Several ROPs have also made provision for the JESSICA finance. But understanding the advantages of the JESSICA form of financing was slow to start up. Currently spring 2010, only in the North Moravia NUST2 and City of Brno plan the use of JESSICA. With the JESSICA approach, technical assistance is being introduced.

\subsection{Reinventing "soft" measures}

A majority of the Czech brownfields, which can actually be reused (if and when there is a sufficient market need for them) are and would be regenerated by the private finance. Hence support of all sorts of "soft" measures to push up skills all around and make it easier for owners and investors, is a very effective solution! "Hard" measures would however be useful for "mitigatory programs", which would remove public risks, but this is not taking place. But even here the "soft" measures would be needed to fill in the missing knowhow on the regional level. Coming to the mid-term review of the SF programs, should not an opportunity been taken to amend the SF programs priorities and direct further funding into brownfield support "soft" measures? 

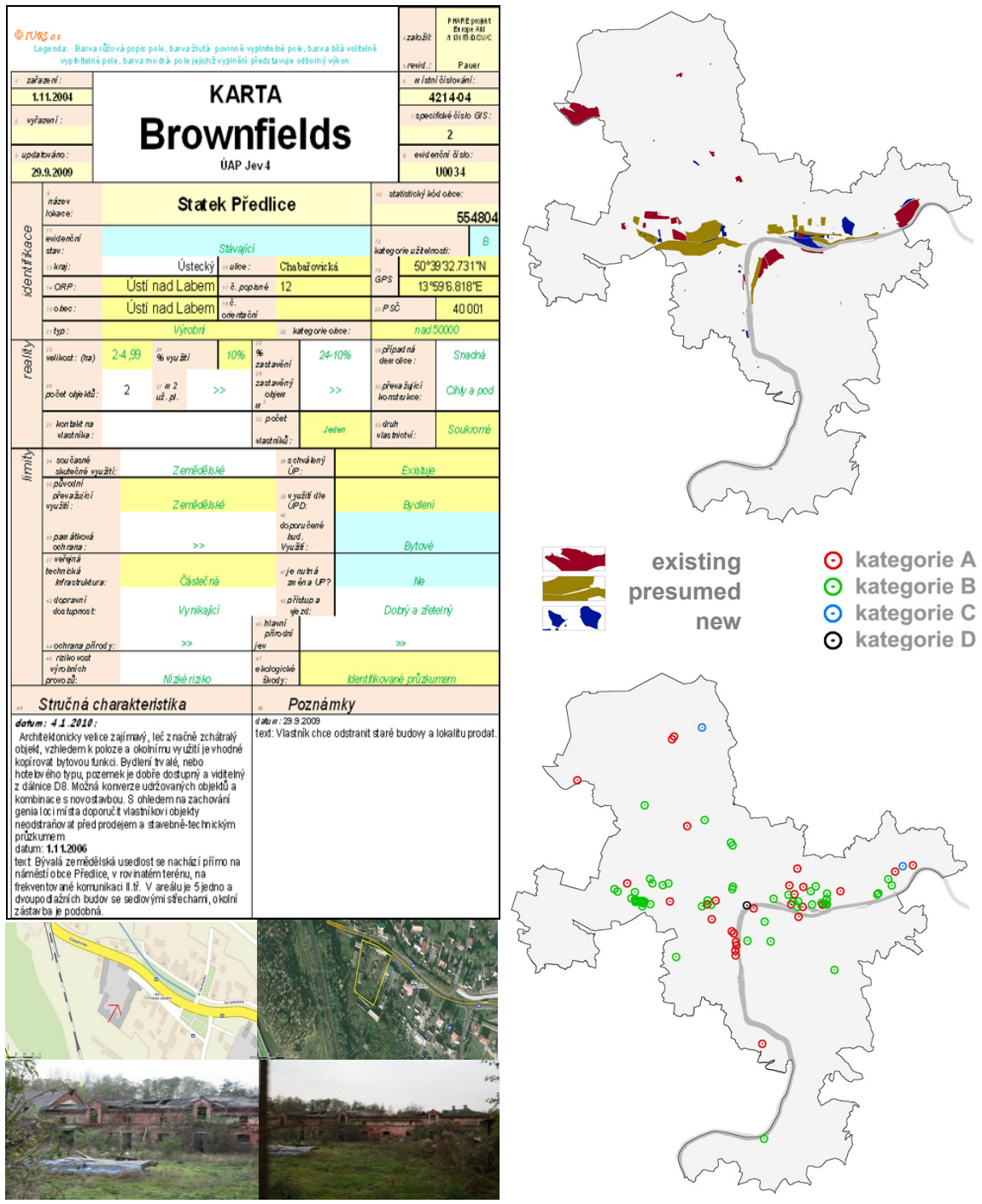

Figure 1: $\quad$ Example of the Brownfield card and communication maps.

Some of such funds should have also been channelled into an update, further exploitation and dissemination of "soft" measures, which have already proved useful (for example LEPOB, BRIBAST and other projects, their Brownfield handbooks and courses, outputs of the COBRAMAN). In this way previously gained skills, knowhow and experience would be capitalised. 

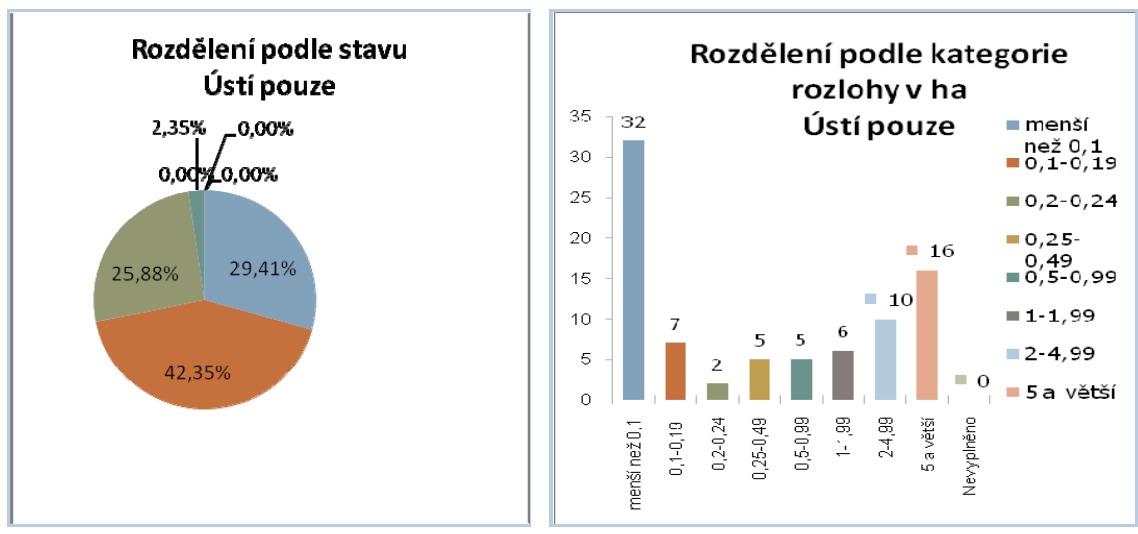

Figure 2: $\quad$ Examples of the inventorying tool automatic analytical output.

Table 1: $\quad$ Example of automatically generated indicators.

\begin{tabular}{|l|c|c|c|c|c|}
\hline \multicolumn{7}{|c|}{ Brownfields indicators -Ústí nad Labem } & 2018 \\
\hline \multicolumn{1}{|c|}{ indicator } & 2010 & 2012 & 2014 & 2016 & 2018 \\
\hline Number of brownfields & $\begin{array}{c}83 \\
(61)\end{array}$ & & & & \\
\hline Brownfields' area & $\begin{array}{c}428 \mathrm{ha} \\
(204 \mathrm{ha})\end{array}$ & & & & \\
\hline Brownfields regeneration index & $0,54 \%$ & & & & \\
\hline $\begin{array}{l}\text { Brownfields \% from the City build up } \\
\text { area }\end{array}$ & $\begin{array}{c}11,7 \% \\
(5,6) \%\end{array}$ & & & & \\
\hline $\begin{array}{l}\text { \% of brownfields from land designated } \\
\text { for development }\end{array}$ & $201 \%$ & & & & \\
\hline $\begin{array}{l}\text { Yearly development increment } \\
\text { compared to brownfields land }\end{array}$ & $?$ & & & & \\
\hline $\begin{array}{l}\text { \% of brownfields from the City } \\
\text { administrative areal. }\end{array}$ & $\begin{array}{c}4,55 \% \\
(2,17)\end{array}$ & & & & \\
\hline
\end{tabular}

\section{Conclusion}

The initial inventorying of brownfields in the Czech Republic targeted onto the single large industrial reuse remediation was only partially useful. It had a little spatial or urban context. By being a sectoral inventory (Ministry of Industry), it was not very suitable for regional or local use. The regional and local users needed brownfields of all types, sizes and "impediments" included. (For an example the CzechInvest inventory has also not listed brownfields, which were located in the 100 years and bellow flood plains). Such an absence of broader brownfield data, have also caused some difficulties in priorities setting and project selection in the present wave of SF, especially in the ROPs.

The new Czech Construction law gave the opportunity to obtain very comprehensive and updatable data sets. But the lack of brownfields skills in the relevant sectoral ministry (the Ministry of Regional Development (MMR)) 
resulted in a total absence of usable methodology how to carry out brownfield inventorying. This shortcoming lead to 14 different regional and 205 ORP approaches how to do it. This is a bit of an embracement to the MMR, and it is by all means not the only teething problem of the new planning support system. So the MMR is not too active to look for a single "item 4" remedy. On the regional bases, the aesthetics of the regional brownfield databases (run mostly by the strategic development departments) became more important than their analysable content, quality and comparability of the data sets. (But the similar applies for the other New Member States - for example the expensive Silesia region brownfield database was recently found unsuitable, incomplete and obsolete). The regions have just recently invested sizable amount of money in these databases, but they are not too keen to take a coordinating and training role for their ORPs, which have the legal obligation to record brownfield property....

So to cohere and motivate approach to brownfield data collection in the Czech Republic is proving quite tedious and difficult. An absence of comparable brownfield data would also hinder the regional and national help, which "theoretically" now could be provided to the most effected Czech local authorities under the auspices of the recently passed National Urban Policy Framework (May 2010). Presently the second round of the UAP GIS layers data gathering is taking place and the Czech brownfields inventory information contained in the "item 4", is due to be updated in the 205 different manners for the second time. It is a pity that despite that the Czech Republic legal framework allowing for identification of brownfields is probably one of the best in the EU, its actual implementation is quite an another thing! Let us hope that in the 2012, the brownfield data could already be gathered in a more comparable manner.

\section{References}

[1] Czech Brownfield Regeneration Strategy, Closing report, CSF, PHARE project EuropeAid/113183/D/SV/CZ, lead consultant Parsons Brinckerhoff (2004]

[2] Czech Planning and Construction law -Stavební zákon č. 183/2006 Sb.

[3] Pořizování územně analytických podkladů. Metodický návod, MMR, UUR. 2009:

[4] Metodika inventarizace brownfieldů v úrovni ORP, Subcontract for the Magistrát města Ústi nad Labem, project COBRAMAN, 1CE014P4, program CENTRAL EUROPE, J.Bergatt Jackson, J. Votoček, IURS2010

[5] Degree 500/2006 Sb., enclosure 1A

[6] COBRAMAN - Program Central Europe http://www.cobraman-ce.eu

[7] BRIBAST - Brownfields in Baltic States - Lifelong Educational Programinnovation transfer project, http://fast10.vsb.cz/bribast

[8] LEPOB - Lifelong Educational Project on Brownfields, Leonardo da Vinci program project, 2004-2006, http://fast10.vsb.cz/lepob Web page for the Czech Structural Funds, $w w$ w.structuralni-fondy.cz

[9] Brownfield database run by the CzechInvest http://www.brownfieldy.cz/, 
PII-26 Brownfields V

[10] Brownfield database run by the Zlín region http://www2.kraj-lbc.cz/ index.php?page $=3531$

[11] Brownfield database run by the Liberec region http://mapy.kr-zlinsky.cz/ ost/bf/

[12] Brownfield database run by the Ústecký region http://www.regenerace.org/ database/U_kraj/search.php

[13] EIB JESSICA http://www.eib.org/projects/publications/jessica.htm 